\title{
Preparation of the Palladium/Polymeric Pyrrole-Multi-Walled Carbon Nanotubes Film/Titanium Electrode and Its Performance for the Dechlorination of 4-chlorophenol
}

\author{
Cuishuang Jiang ${ }^{1}$, Hongbin $\mathrm{Yu}^{1,2, *}$, Xinhong Wang ${ }^{3}$, Ying $\mathrm{Lu}^{1}$, Xubiao Luo ${ }^{2, *}$ \\ ${ }^{1}$ School of Environment, Northeast Normal University, Changchun 130117, China \\ ${ }^{2}$ Key Laboratory of Jiangxi Province for Persistent pollutants Control and Resources Recycle, \\ Nanchang Hangkong University, Nanchang 330063, China \\ ${ }^{3}$ College of Resources and Environment, Jilin Agricultural University, Changchun 130118, China \\ *E-mail: yuhb108@nenu.edu.cn, luoxubiao@126.com
}

doi: $10.20964 / 2017.06 .44$

Received: 28 February 2017 / Accepted: 13 April 2017 / Published: 12 May 2017

The electrochemically reductive dechlorination of 4-chlorophenol (4-CP) in aqueous solution on a palladium/polymeric pyrrole-multi-walled carbon nanotube film/meshed titanium electrode ( $\mathrm{Pd} / \mathrm{PPy}$ MWCNTs/Ti) was examined in this paper. The Pd/PPy-MWCNTs/Ti cathode was prepared through electrodepositing cauliflower-like palladium nanoparticles onto a PPy-MWCNTs/Ti electrode (that was a titanium electrode coated with pyrrole and functionalized multi-walled carbon nanotubes by codeposition). The physical properties of this electrode were characterized by scanning electron microscope (SEM) and X-ray diffraction (XRD). Various factors influencing the dechlorination of 4$\mathrm{CP}$ were also investigated. The results indicated that the removal rate of 4-CP reached $99.82 \%$ within $120 \mathrm{~min}$ and the current efficiency of $13.8 \%$ was obtained under the optimum conditions (the dechlorination density of $1.0 \mathrm{~mA} / \mathrm{cm}^{2}$, the initial $\mathrm{pH}$ of 2.08 and the electrolyte of $0.1 \mathrm{~mol} / \mathrm{L} \mathrm{Na}_{2} \mathrm{SO}_{4}$ ). The predominant product was phenol. In addition, the electrode was found to be still stable after being used for six cycles and the dechlorination efficiency was over $93.3 \%$.

Keywords: Polymeric pyrrole, Multi-walled carbon nanotubes, Palladium, Dechlorination, 4chlorophenol

\section{FULL TEXT}

(C) 2017 The Authors. Published by ESG (www.electrochemsci.org). This article is an open access article distributed under the terms and conditions of the Creative Commons Attribution license (http://creativecommons.org/licenses/by/4.0/). 